\title{
PENATAAN MASSA BANGUNAN PADA LAHAN SEMPIT Studi Kasus : SMK WIDYA DHARMA, TUREN, KAB. MALANG
}

\author{
Gaguk Sukowiyono \\ Dosen Prodi Arsitektur, Fak. Teknik Sipil dan Perencanaan, ITN Malang \\ e-mail: gaguksukowiyono@yahoo.com \\ Debby Budi Susanti \\ Dosen Prodi Arsitektur, Fak. Teknik Sipil dan Perencanaan, ITN Malang \\ e-mail: budisusantidebby@gmail.com \\ Breeze Maringka \\ Dosen Prodi Arsitektur, Fak. Teknik Sipil dan Perencanaan, ITN Malang \\ e-mail: breezemaringka@lecturer.itn.ac.id
}

\begin{abstract}
ABSTRAK
Meningkatnya kebutuhan akan sarana dan prasarana belajar mengajar pada SMK Widya Dharma Turen, Kabupaten Malang mendorong pihak sekolah untuk berusaha memaksimalkan pemanfaatan lahan yang dimilikinya sesuai dengan standar ruang dan kenyamanan bagi seluruh pengguna sekolah tersebut, termasuk juga perancangan ruang luar pada lingkungan sekolah.
\end{abstract}

Kata kunci : lahan, ruang luar, sarana prasarana

ABSTRACT

The increasing need for teaching and learning facilities and infrastructure at SMK Widya Dharma Turen, Malang Regency encourages schools to try to maximize the use of their land according to the standards of space and comfort for all school users, including the design of outdoor spaces in the school environment.

Keywords : land, outer space, infrastructure

\section{PENDAHULUAN}

Kebutuhan akan tenaga kerja yang memiliki keterampilan yang siap dalam penerapan di lapangan kerja saat ini berdampak pula pada perkembangan dunia pendidikan. Minat masyarakat untuk menempuh pendidikan pada sekolah-sekolah kejuruan membawa dampak meningkatnya jumlah siswa dan sekolah kejuruan yang ada. Secara otomatis perkembangan jumlah siswa membawa dampak pada peningkatan kebutuhan ketersediaan sarana dan prasarana belajar mengajar bagi siswa dan tenaga pendidik. Pola pendidikan yang diterapkan pada sekolah kejuruan yang identik dengan pembekalan keterampilan bagi anak didiknya diyakini mampu mencetak lulusan yang siap untuk terjun langsung ke dunia 
lapangan kerja.

Demikian juga dengan SMK Widya Dharma Turen yang berada di wilayah Kabupaten Malang. Seiring dengan meningkatnya jumlah siswa yang masuk ke sekolah tersebut membuat pihak sekolah berusaha menambah dan memenuhi kebutuhan sarana dan prasarana yang ada di lingkungan sekolah tersebut. Akan tetapi tingginya harga lahan saat ini mengakibatkan pihak sekolah merasa kesulitan untuk menambah luasan lahannya. Sehingga salah satu cara yang direncanakan oleh pihak sekolah adalah dengan mengoptimalkan lahan yang ada saat ini untuk dapat menampung pertambahan jumlah siswa beserta seluruh aktfitasnya.

\section{TINJAUAN PUSTAKA}

\subsection{Fasilitas Olah Raga}

Sarana olahraga merupakan salah satu fasilitas yang ingi disediakan oleh pihak sekolah agar para siswa tidak perlu lagi berjalan dengan jarak yang cukup jauh untuk dapat mencapai lapangan olah raga terdekat dari sekolahnya. Sesuai dengan minat dan bakat yang dimiliki para siswanya, lapangan oleh raga yang ingin disediakan di dalam lahan sekolahya adalah lapangan basket, lapngan badminton, dan lapangan tenis. Menurut kajian pustaka yang sudah dilakukan, standar ukuran untuk masing-masing lapangan tersebut adalah sebagai berikut :

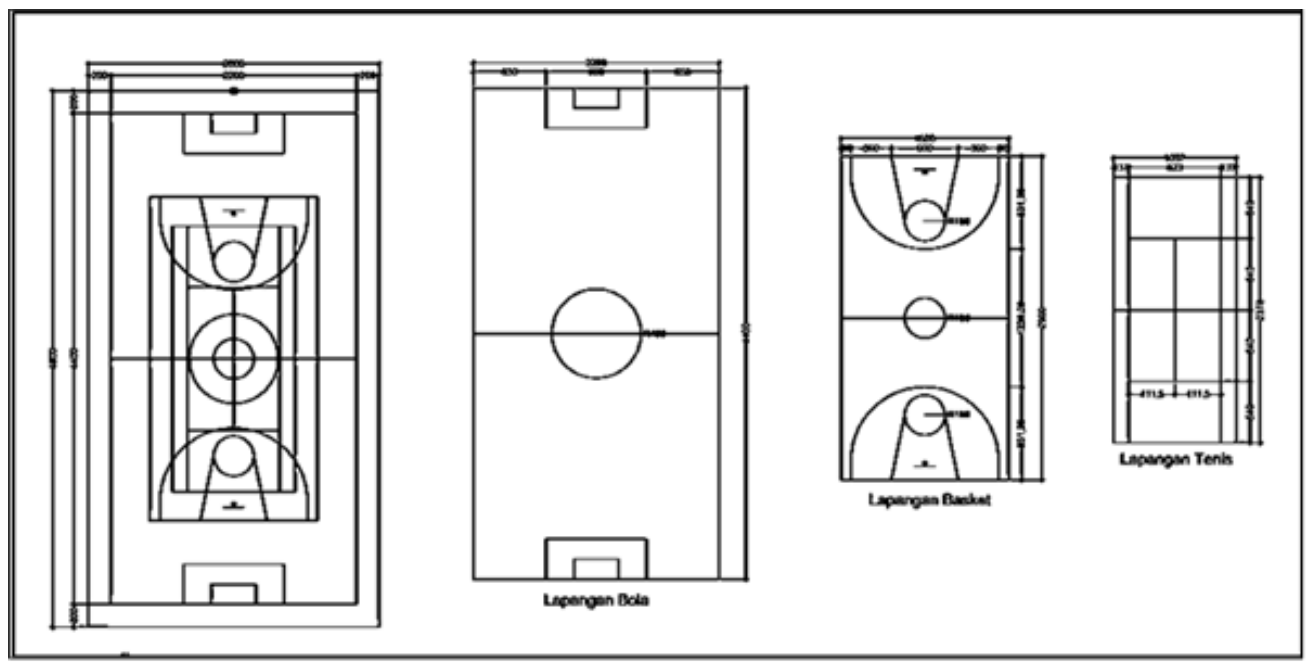

Gambar Standar ukuran lapangan. 


\subsection{Gerbang dan Jalan Masuk}

Pihak sekolah mengingkan agar gerbang dan jalan masuk juga didesain untk melengkapi kebutuhan para siswa, dengan lebar jalan yang dirancang yaitu $3 \mathrm{~m}$, gerbang dan jalan ini berada di sisi barat lahan. Berdasarkan data ukuran panjang jalan yang akan dibuatkan ini didapat dari sumber Google Earth, kemungkinan panjang jalan tersebut $\pm 170 \mathrm{~m}$ (belum tentu sesuai dengan ukuran yang ada di lokasi).

\subsection{Gedung Aula}

Dari pihak sekolah meminta untuk merancang gedung aula yang dapat menampung kegiatan-kegiatan yang diadakan pihak sekolah dengan keterbatasan lahan yang dimiliki sekolah. Disamping keterbatasan lahan yang dimiliki, pihak sekolah juga meminta untuk membuat sarana penghubung berupa taman antara gedung aula dengan gedung yang ada di sekitar aula seperti grdung-gedung kelas.

\subsection{Area Duduk}

Area duduk menjadi salah satu objek masyarakat yang diminta. Area duduk sebelumnya merupakan tempat parkir. Area duduk diminta adalah sebagai tempat berdiskusi dan belajar untuk siswa di SMK Widya Dharma Turen. Ukuran dari area duduk adalah 19,5 meter x 9,6 meter. Di area duduk ini juga diminta dengan desain yang teduh dan tampak asri.2.5. Penghubung Antar Massa

Ukuran dari lahan yang akan dibuat Taman A ini adalah 17,75 meter $\mathrm{x}$ 15,80 meter. Suasana pada tapak juga terasa gersang sehingga dibutuhkan ruang penghubung yang tidak hanya memiliki nilai estetika yang apik, namun bisa memberikan kesan teduh dan asri bagi orang yang lewat di taman tersebut. Taman B yang didesain ini merupakan ruang penghubung juga, tetapi tampak kosong dan gersang karena hanya ada beberapa pohon dan air mancur. Ukuran dari Taman B adalah 17 meter x 29 meter.

\section{METODE PERANCANGAN}

Visit lapangan perlu dilakukan untuk mengetahui dan memahami kondisi lokasi tapak dan lingkungannya secara detail. Dari hasil pendataan awal kawasan perencanaan secara fisik pada kawasan SMK Widya Dharma Turen dan lingkungan dapat digambarkan bahwa letak SMK Widya Dharma Turen berada di sekitar lahan persawahan, kebun/ladang, lahan kosong, serta beberapa hunian yang relatif masih jarang dan cukup jauh dari sekolahan. Aksesibilitas masuk ke sekolahan berupa jalan beraspal dengan lebar $\pm 4.00 \mathrm{~m}$. Jalan ini merupakan satu-satunya jalan yang digunakan oleh sekolahan dan masyarakat sekitar yang membujur ke arah Utara dan Selatan 


\section{HASIL DAN PEMBAHASAN}

\section{a. Lapangan Olah Raga}

Berdasarkan data lapangan yang sudah didapatkan, selanjutnya dimulai untuk membuat alternatif rancangan desain lapangan olahraga lengkap dengan fasilitas yang dibutuhkan dengan hasil sebagai berikut :

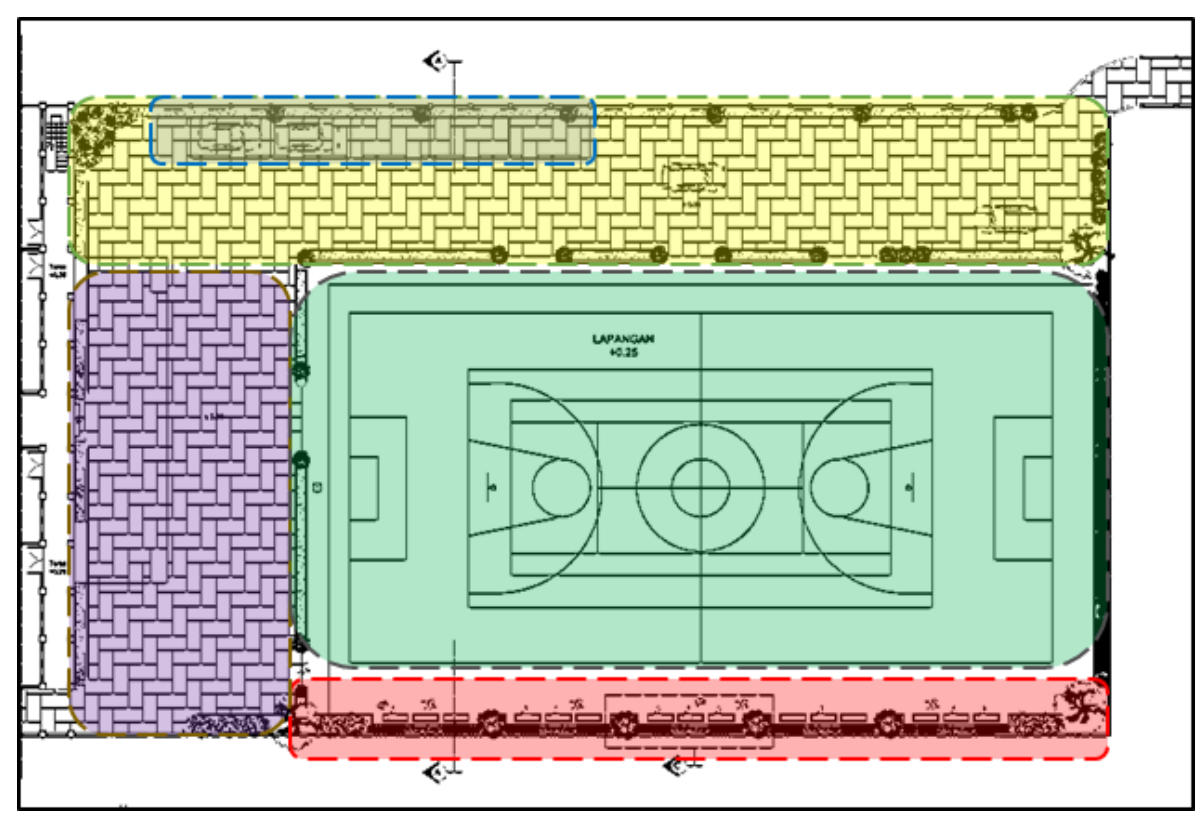

- Area Lapangan Upacara dan Lapangan Olahraga

- Area Duduk dan Taman

- Area Jalan

- Area Parkir

- Area Drop Off 


\section{b. Jalan Masuk dan Gerbang}

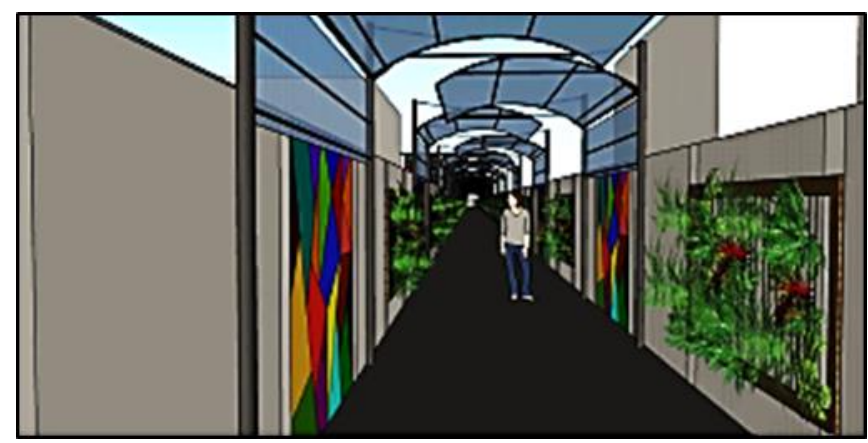

Di sepanjang dinding pagar jalan masuk diberi tanaman vertikal, kanopi dan corak mural pada dinding. Tujuan diberi tanaman vertikal ini agar dapat memberikan kesan yang asri dan juga memberikan udara segar disepanjang jalan tersebut. Kemudian dinding-dinding ini juga diberi corak mural agar setiap siswa/i maupun para guru yang melewati jalan tersebut tidak merasa bosan dan penambahan kanopi di sepanjang jalan ini agar apabila hujan datang, para siswa/i yang melewati jalan tersebut tidak terkena basah. Dengan adanya penambahan tanaman vertikal, corak mural, dan juga kanopi ini dapat memberikan kesan yang tidak bosan bagi orangorang yang melewatinya.

\section{c. Gedung Aula}

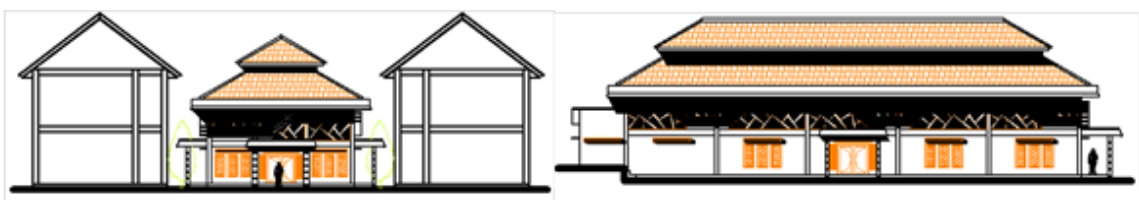

Desain gedung aula ini tidak terbuka karena didesain seperti aula pada umumnya yaitu tertutup menggunakan dinding. Walaupun tertutup dinding, pencahayaan dan penghawaan alami pada desain ini tetap diperhatikan dengan memberikan bukaan berupa ventilasi dan jendela yang cukup banyak pada keseluruhan bangunan. Selain ventilasi dan jendela, pada bagian atap pun diberi bukaan agar lebih memaksimalkan sirkulasi udara didalam aula sehingga kenyamanan dalam gedung aula dapat tercapai. 


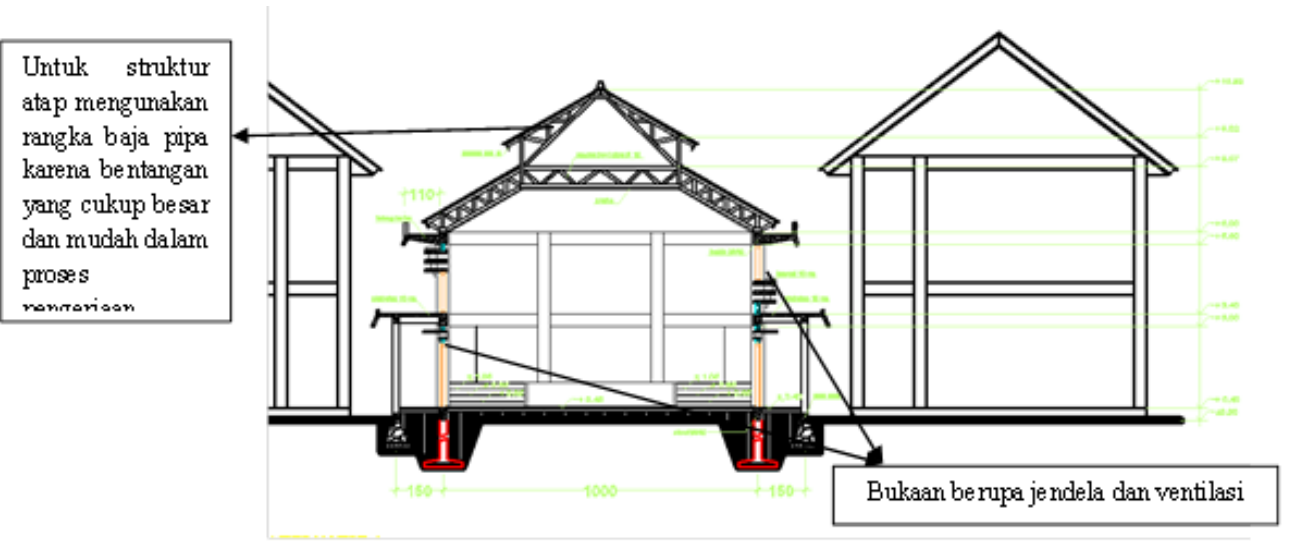

\section{d. Area Taman}

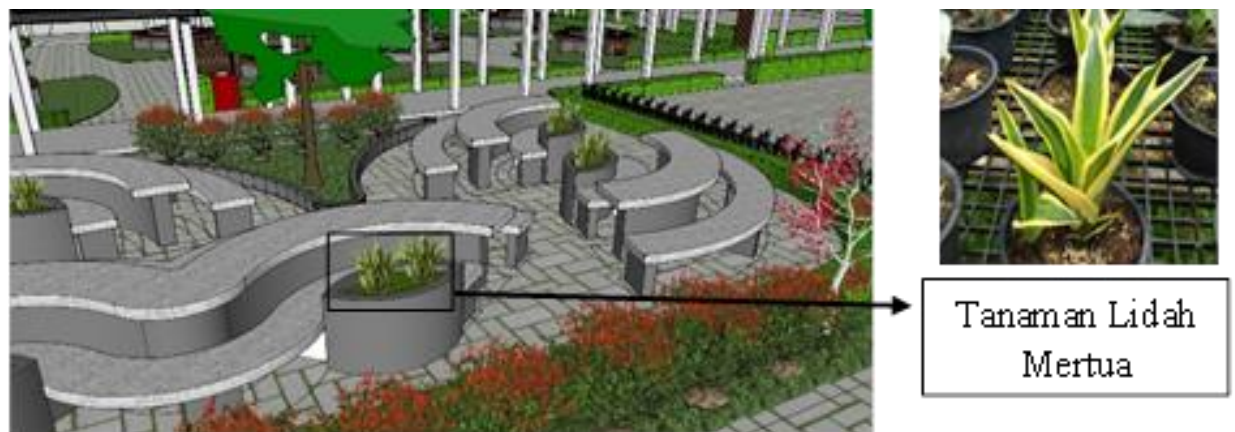

Area duduk dikonsepkan di tengah dengan sedikit taman disekelilingnya. Desain bentuk kursi dan meja dibuat dinamis dengan menyesuaikan dari bentuk Taman A dan Taman B. Bentuk kursi dan meja dibuat dinamis atau melengkung dengan tatanan ruang sosiopetal untuk menciptakan interaksi sosial. 


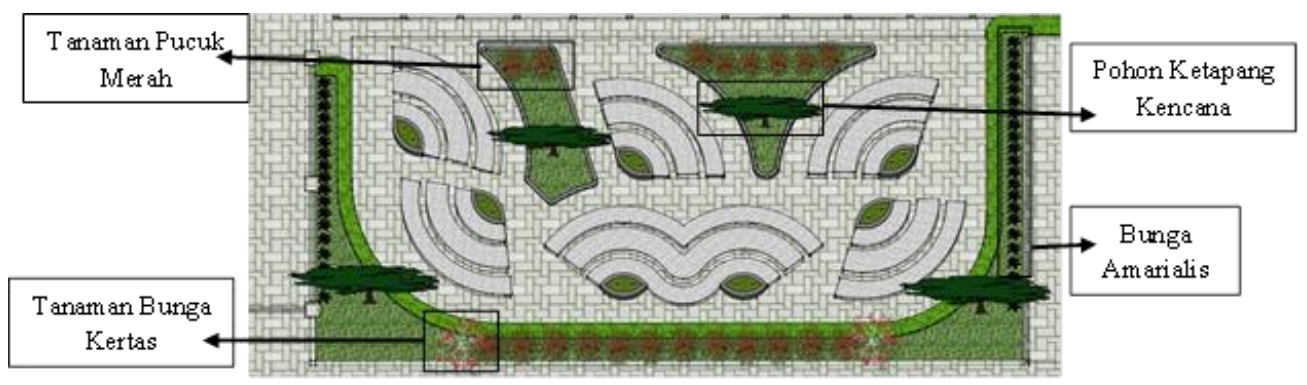

Pada bagian kursi terdapat pot yang ditanami lidah mertua. Menggunakan lidah mertua karena banyak mengeluarkan $\mathrm{O} 2$ dan menyerap CO2 sehingga sangat baik berada dekat dengan kursi karna disana mereka berinteraksi.

\section{KESIMPULAN}

Perencanaan sebuah bangunan sekolah selain harus memperhatikan kondisi tapak dan eksistingnya, juga harus memperhatikan studi perilaku terhadap pengguna bangunan, sehingga hasil rancangan yang dihasilkan benar-benar dapat mewadahi seluruh aktifitas yang ada nantinya. 


\section{DAFTAR PUSTAKA}

7. Ernest Neufert. 1994. Data Arsitek, Edisi Kedua Jilid 1. Erlangga. Jakarta

8. Ernest Neufert. 1994. Data Arsitek, Edisi Kedua Jilid 2. Erlangga. Jakarta

9. Gunadi, Sugeng. 1989. Pdoman Perancangan Tapak dan Lingkungan. Utama Press. Surabaya.

10. Galllion and Eishner. 1992. Pengantar Perancangan Kota. Erlangga. Jakarta.

11. Hakim, Rustam. 1993. Unsur Perancangan Dalam Arsitektur Lansekap. Penerbit Bumi Aksara. Bandung.

12. Joyce Marcella Laurens. 2004. Arsitektur dan Perilaku Manusia. Grasindo. Jakarta 